\title{
PSA Level Greater than 0.5
}

National Cancer Institute

\section{Source}

National Cancer Institute. PSA Level Greater than 0.5. NCI Thesaurus. Code C160868.

A blood concentration of prostate specific antigen greater than $0.5 \mathrm{ng} / \mathrm{mL}$. 